Session 332

\title{
Innovative Modern Engineering Design and Rapid Prototyping Course: A Rewarding CAD/CAE/CAM Experience for Undergraduates
}

\author{
Il Yong Kim, Olivier de Weck, William Nadir, Peter Young and David Wallace \\ Department of Aeronautics and Astronautics and Engineering Systems Division \\ Massachusetts Institute of Technology \\ Cambridge, Massachusetts 02139
}

\begin{abstract}
This paper presents a new undergraduate design course in the Department of Aeronautics and Astronautics at MIT. This course combines design theory, lectures and hands-on activities to teach the design stages from conception to implementation. Activities include hand sketching, CAD, CAE, CAM, design optimization, rapid prototyping, and structural testing. The learning objectives, pedagogy, required resources and instructional processes as well as results from a student assessment are discussed.
\end{abstract}

\section{Introduction}

A recent survey of undergraduate students in the Department of Aeronautics and Astronautics at MIT has shown that there is a desire for training in modern design methods using state-of-the-art $\mathrm{CAD} / \mathrm{CAE} / \mathrm{CAM}$ technology and design optimization. Individual students have suggested the addition of a short and intense course in rapid prototyping, combined with design optimization. The specific reference from the student survey is paraphrased here:

"The CDIO [conceive-design-implement-operate] initiative has been well received by undergraduates, who have thoughtful suggestions for improvements. Some feeling of imbalance between fundamentals and other skills. Offerings in CAD/CAM, machining, fabrication desired."

The intent of this course is to respond to this perceived gap, while exploiting synergies with other engineering departments that have articulated similar needs. We have developed an intense 6 -credit-unit IAP (independent activities period) ${ }^{1}$ course that takes students through the conception, design, and implementation of a single, complex structural component. This activity supports the learning objectives of the Conceive-Design-Implement-Operate (CDIO) initiative $[1,2,3]$ and leverages the latest technologies in computer-assisted design, analysis, optimization, and rapid prototyping. The novelty of this course lies in its combination of rapid prototyping with design optimization in order to demonstrate the complementary capabilities of humans and computers during the design process.

The overall learning objective of this activity is for students to develop a holistic view of and initial competency in engineering design by applying a combination of human

\footnotetext{
${ }^{1}$ IAP is a one-month alternative period during January of each academic year at MIT. The course was offered under the number 16.682 in 2004 and will carry the number 16.810 in the future.
}

Proceedings of the 2004 American Society for Engineering Education Annual Conference \& Exposition 
creativity and modern computational methods and tools to the synthesis of a complex structural component.

This goal can be mapped onto the following learning objectives of the CDIO syllabus [2]:

- Core Engineering Fundamental Knowledge: solid mechanics \& materials

- Advanced Engineering Fundamental Knowledge: computational techniques

- Engineering Reasoning and Problem Solving: modeling

- Personal Skills and Attitudes: creative thinking

- Conceiving and Engineering Systems: modeling systems and ensuring goals can be met

- The Design Process: execute appropriate optimization in the presence of constraints

- Implementing: hardware manufacturing process

- Implementing: test, verification, validation, and certification

This paper first offers a description of the course, focusing on its structure and flow (Section 2). Next, the target student population (Section 3) and required resources (Section 4) will be discussed. The design project, including the requirements levied on the students, is the subject of Section 5. In Section 6, we explain how design optimization can be incorporated in such design courses. An overview of the student deliverables (Section7), assessment results (Section 8) and conclusions (Section 9) round out the paper.

\section{Course description}

The goal of the course is to provide the students with an opportunity to conceive, design, and implement products quickly and effectively, using the latest rapid prototyping methods and $\mathrm{CAD} / \mathrm{CAE} / \mathrm{CAM}$ technology. This is meant to be an intense and satisfying experience that emphasizes the chain of design steps shown in Figure 1.

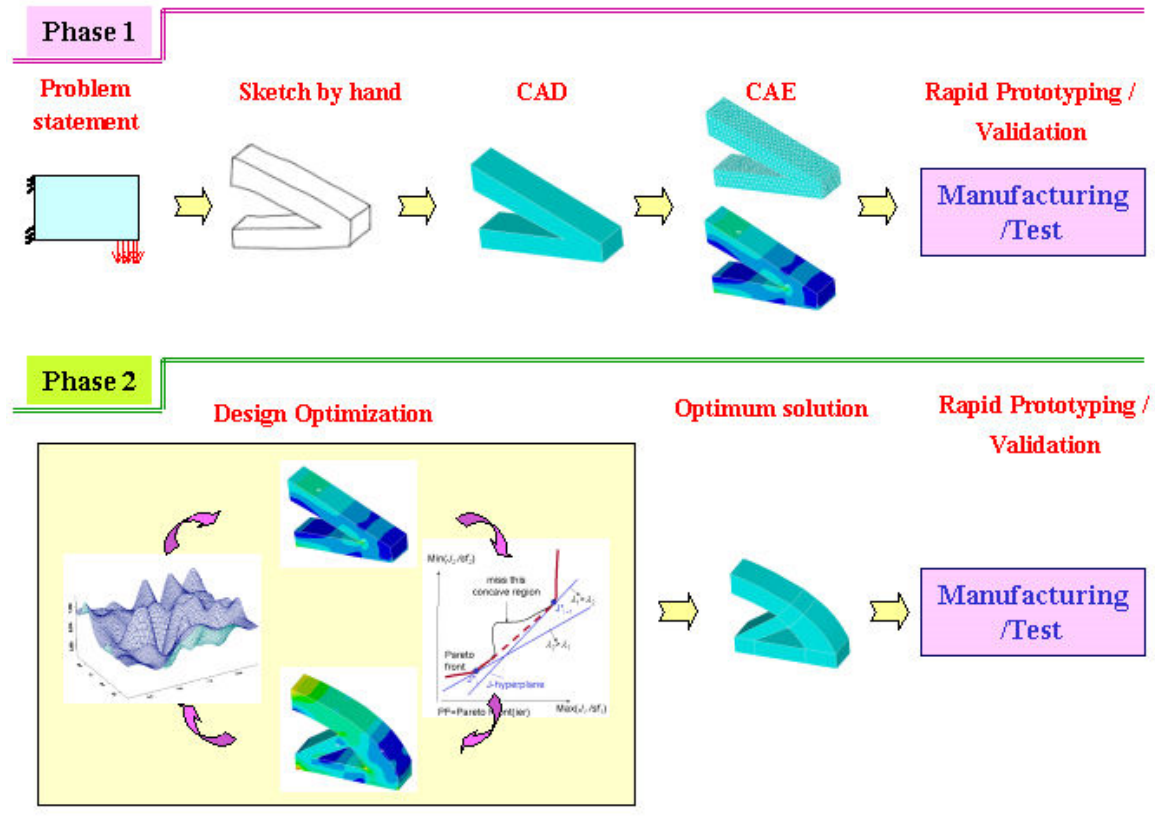

Figure 1: Engineering Design and Rapid Prototyping: course pedagogy 


\section{Course Pedagogy and Concept}

Fundamental engineering design principles and procedures are introduced and in some cases reviewed during the first week [4-6]. The idea of structuring the course in two phases is rooted in the following cognitive progression:

In the first phase, the students are presented with solution neutral requirements and constraints for a structural component. Teams of two students are formed and each team receives slightly different requirements (see Section 5). A creative process of hand sketching is followed by computer aided design (CAD) and analysis (CAE). This helps the students ascertain that their Phase 1 design will theoretically meet the requirements. After some manual iteration, the part specification is implemented on water jet cutting equipment. The prototype is subjected to structural testing in the laboratory to verify the validity of the predictions as well as requirements compliance.

The second phase takes the Phase 1 manual design as an input and improves the solution via design optimization. In effect, the earlier manual solution is used as an initial condition for the design optimization step. This is what ties Phases 1 and 2 together. The students conduct design optimization using either commercial or faculty-provided software. The optimum solution obtained is modeled as a CAD model, and again computer numerically controlled (CNC) equipment is used to fabricate the improved component. The optimized component is compared with the hand-designed one, and conclusions are drawn.

The course concludes with student presentations culminating in a "Critical Design Review", and potentially a competition, which includes results from testing of the initial and optimized designs. This side-by-side comparison helps produce several educational insights:

- Understanding of the predictive accuracy of CAE modeling versus actual test results

- Understanding of the relative improvement that computer optimization can yield relative to an initial, manual solution

- Illustration of the capabilities and limitations of the human mind and digital computer during design and manufacturing

\section{Course Flow}

The course plan starts by exposing the students to the design process, its phases, and the importance of properly formulated requirements. An introduction to state-of-the-art $\mathrm{CAD} / \mathrm{CAE} / \mathrm{CAM}$ environments is given during the first week. Initial hands-on activities include hand sketching, creating engineering drawings, and CAD Modeling. Due to the time limitations of this IAP course, compromises have to be made with respect to the breadth and depth of some of the topics that are covered. Emphasis is placed on successfully completing the various steps of the design process, rather than understanding all the details of the methods and tools used along the way. Assumptions outlined in Section 5 limit the complexity of this undertaking in order to avoid overwhelming the students and to ensure that they focus on the learning objectives. A flowchart of the class activities, which includes student deliverables, is shown in Figure 2. 


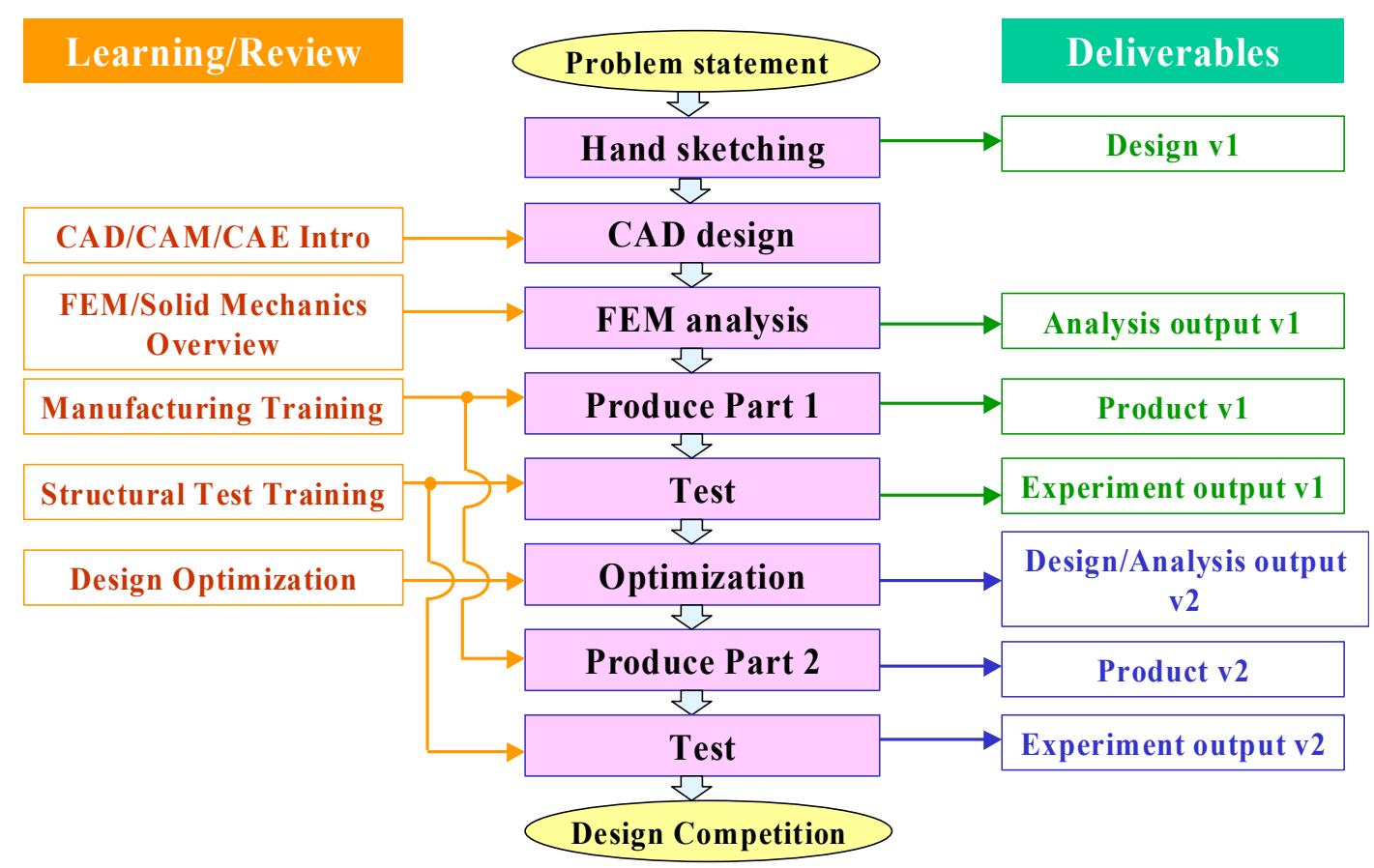

Figure 2: Flowchart of Engineering Design and Rapid Prototyping class

Table 1 shows the detailed course schedule. Each class consists of a lecture on theory ( 1 hour and 30 minutes) directly followed by a hands-on activity (1 hour and 30 minutes). The first seven classes constitute Phase 1, and the remaining four classes make up Phase 2. Two sessions are devoted to design optimization because of its complexity. Other activities in Phase 2, such as CAD modeling, manufacturing, and testing, can be done quickly because students have already acquired most of these skills in Phase 1. Two guest lectures provide the students with opportunities to learn about current practices and challenges in industry.

Table 1 Course Schedule

\begin{tabular}{|c|c|c|c|c|}
\hline & Week & Monday & Wednesday & Friday \\
\hline \multirow{2}{*}{1} & Lecture & $\begin{array}{l}\text { L1 - Introduction } \\
\text { (de Weck) }\end{array}$ & $\begin{array}{l}\text { L2 - Hand Sketching } \\
\text { (Wallace) }\end{array}$ & $\begin{array}{l}\text { L3 - CAD modeling } \\
\text { ( Kim, de Weck) }\end{array}$ \\
\hline & $\begin{array}{l}\text { Hands-on } \\
\text { activities }\end{array}$ & $\begin{array}{c}\text { Tour - Design studio } \\
\text { - Machine shop } \\
\text { - Testing area }\end{array}$ & Sketch Initial design & $\begin{array}{l}\text { Make a 2-D CAD model } \\
\text { (Solidworks) Nadir }\end{array}$ \\
\hline \multirow{2}{*}{2} & Lecture & $\begin{array}{l}\text { L4 - Introduction to CAE } \\
\text { (Kim) }\end{array}$ & $\begin{array}{l}\text { L5 - Introduction to CAM } \\
\text { (Kim) }\end{array}$ & $\begin{array}{l}\text { L6 - Guest Lecture } 1 \text { (Bowkett) } \\
\text { Rapid Prototyping }\end{array}$ \\
\hline & $\begin{array}{c}\text { Hands-on } \\
\text { activities }\end{array}$ & FEM Analysis (Cosmos) & $\begin{array}{l}\text { Water Jet Intro machine shop } \\
\text { Omax (Weiner, Nadir) }\end{array}$ & Make part version 1 \\
\hline \multirow{2}{*}{3} & Lecture & $\begin{array}{l}\text { Martin Luther King Jr. } \\
\text { Holiday - no class }\end{array}$ & $\begin{array}{l}\text { L7 - Structural Testing } \\
\text { (Kim, de Weck) }\end{array}$ & L8 - Design optimization (Kim) \\
\hline & $\begin{array}{c}\text { Hands-on } \\
\text { activities }\end{array}$ & & Test part ver. 1 (Kane) & $\begin{array}{l}\text { Introduction to Structural } \\
\text { Optimization Programs }\end{array}$ \\
\hline \multirow{2}{*}{4} & Lecture & & & \begin{tabular}{|l} 
L9 - Guest Lecture 2 (Sobieski) \\
Multidisciplinary Optimization
\end{tabular} \\
\hline & $\begin{array}{l}\text { Hands-on } \\
\text { activities }\end{array}$ & Carry out design optimization & $\begin{array}{l}\text { Manufacture part ver. } 2 \\
\text { Test part ver. } 2\end{array}$ & Final Review (de Weck, Kim) \\
\hline
\end{tabular}




\section{Student target population}

The initial offering of the class was limited to 18 students, broken down into 9 teams of two students each. Because the class is laboratory oriented, such a small number of students is preferable. In addition, the number of seats in the Design Studio and the capacity of the machine shop are inherently limited. The target level were seniors ( $4^{\text {th }}$ year) and juniors $\left(3^{\text {rd }}\right.$ year $)$ who already have basic knowledge of mechanics, engineering mathematics, and design. The course is targeted primarily to undergraduate students with special emphasis on Aerospace and Mechanical Engineering.

This course is offered as an elective and seeks to attract students who want to:

(1) Experience the conceive-design-implement-operate process for a single, complex component using the latest $\mathrm{CAD} / \mathrm{CAE} / \mathrm{CAM}$ technology.

(2) Understand the subtleties of complementary human design abilities and computer strengths in optimization.

(3) Understand the predictive accuracy of CAE modeling versus actual laboratory test results.

(4) Obtain 6 units of credit without imposing additional scheduling constraints during the regular semesters.

\section{Resources}

We use Matlab as a general computing environment for this course. The SolidWorks and Cosmos package is used for CAD design and finite element analysis, respectively. All the lectures and computer-based hands-on activities are performed in a Design Studio (Fig. 3a). This concurrent engineering facility is comprised of 14 networked CAD/CAE workstations that are used for complex systems design and optimization. An abrasive waterjet cutter with OMAX CAM software is used for rapid prototyping in the department's machine shop (Fig. 3a). We have manufactured a dedicated testing fixture to enable fast testing, as shown in Fig. 3 (c).

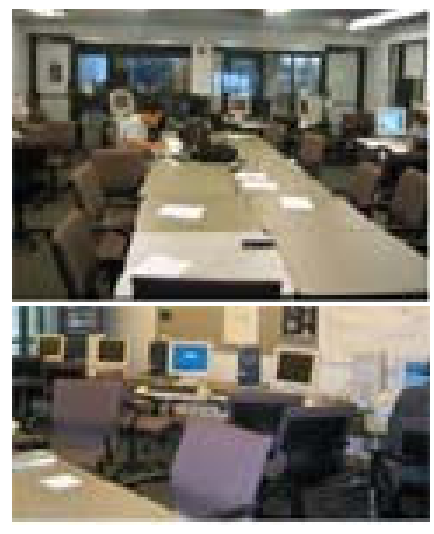

(a) Design studio

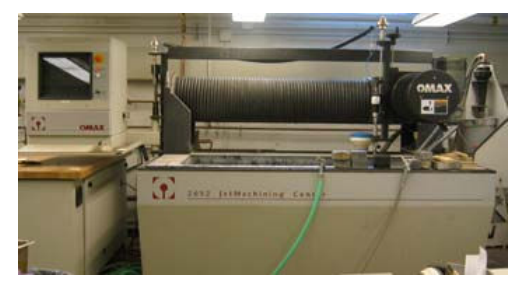

(b) Abrasive water-jet cutting machine

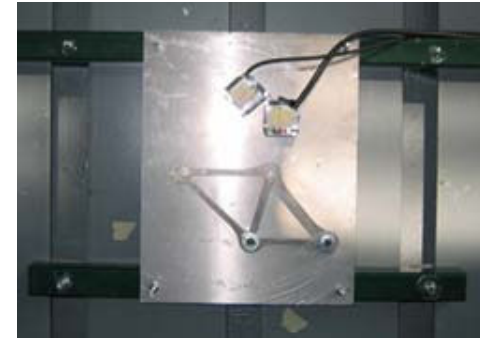

(c) Fixture for testing (test article installed)

Figure 3: Design studio, abrasive waterjet, and fixture for testing 


\section{Project description}

This section describes the design project that was used during the initial offering (2004). The project is limited to a single structural component with medium complexity (some boundary conditions, one single-load case, some functional surfaces, and forbidden zones given). The maximum part dimensions are approximately 12 " x 12 " x 0.5 ". No assemblies, machines, or mechanisms were produced. The part complexity might be modified in future years as we learn more about feasibility, student ability, and time constraints. We limited the design task to two dimensions. This significantly simplified hand sketching and CAD modeling. The parts still had to fulfill three-dimensional requirements (e.g. first natural frequency).

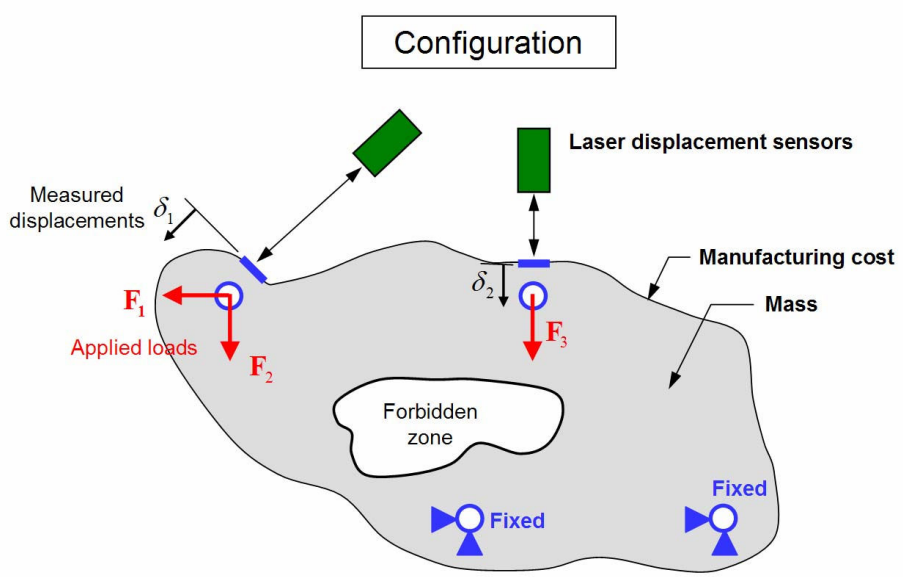

(a)

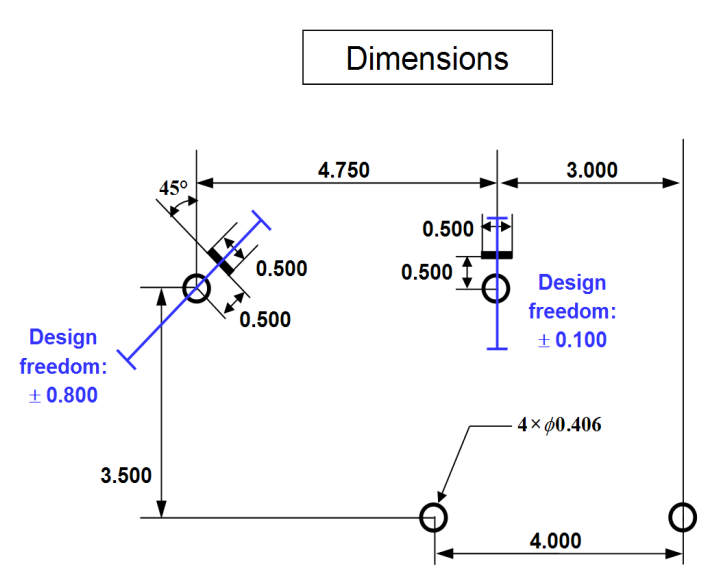

(b)

Figure 4: Configuration and dimensions of the design requirement

Figure 4 shows the configuration and dimensions associated with the design requirement. The requirement is based on a simplified bicycle frame model. The lower two holes are fixed, and three loads $F_{1}, F_{2}$ and $F_{3}$ are applied to the two upper holes (Fig. 4a). These forces represent the fork and saddle loads. A fixture with two laser sensors was fabricated and used for structural testing, see Figure 3 (c), in order to obtain measurements of the displacements, $\delta_{1}$ and $\delta_{2}$.

The class had nine teams of two students each. Every team carried out a surrogate bicycle frame design for a different hypothetical market segment. The nine market segments were as follows: Consumer division: Family economy, Family deluxe, Cross over, City bike, Specialty division: Racing, Mountain, BMX, and Acrobatic, Motor division: Motor bike. During the last week of the course, the students visited a leading, local bicycle frame manufacturer [8], where they saw first hand that designing products based on the needs of differentiated market segments is very relevant in the real world.

Load magnitude, design requirements, and design priorities vary according to the market segment.

A sample requirement, which is handed to students in the first week, is given below. 
Sample Design Requirements

\section{Market Segment: Family Economy}

\section{(a) Market Description}

This bicycle is to be designed for the mass consumer market. The expected sales volume is 100,000 per year. The requirements of affordability, excellent performance/cost ratio, and low weight are most important to be successful in this market.

\section{(b) Requirements}

Manufacturing Cost $(\mathrm{C})$ :

$\mathrm{C} \leq 3.6 \$$ part

Performance $\left(\delta_{1}, \delta_{2}, f_{1}\right)$ :

Displacement $\delta_{1} \leq 0.078 \mathrm{~mm}$

Displacement $\delta_{2} \leq 0.012 \mathrm{~mm}$

First natural frequency $\mathrm{f}_{1} \geq 195 \mathrm{~Hz}$

$\underline{\text { Mass }}(\mathrm{m})$ :

$\mathrm{m} \leq 0.27 \mathrm{lbs}$

Surface Quality (Q):

$\mathrm{Q} \geq 2$

Load Case $(F)$ :

$\mathrm{F}_{1}=50 \mathrm{lbs}, \mathrm{F}_{2}=50 \mathrm{lbs}, \mathrm{F}_{3}=100 \mathrm{lbs}$

The part has to conform to the interface requirements and geometrical boundary conditions shown in this document. This requirement cannot be waived.

\section{(c) Priorities}

Low manufacturing cost is the first priority for this product. Next, the customer prefers a low weight product, and thirdly, structural performance should be as high as possible. These priorities are shown in the Ishii-matrix below:

Table 2 Ishii's matrix for design requirement

\begin{tabular}{|c|c|c|c|}
\hline Attribute & Constrain & Optimize & Accept \\
\hline Cost & & & \\
\hline Performance & & & \\
\hline Mass & & & \\
\hline
\end{tabular}

\section{Design Optimization}

The students conducted structural topology optimization, based on a pixel-like approach. We utilized web-based optimization that was developed by Tcherniak and Sigmund [7]. This optimization software can solve two-dimensional problems with rectangular design domains with a maximum number of 1000 design cells. If a cell has a density of one, it means material should be used in the cell. Compliance is used as the objective function, and the constraint is the volume fraction. This topology optimization is used to determine improved design layouts. Because the design requirements in Section 5 have other performance metrics, it is not possible to use this software for optimization considering all of our performance metrics of interest. For future years, we intend to develop an optimization environment that is easy to use and complements the webbased tool. Optimum designs cannot (yet) automatically be imported to CAD software. When 
optimum solutions are obtained, students must interpret them and create CAD designs on their own. Figure 5 shows the graphical user interface (GUI) of the web-based optimization software and a sample optimization result.

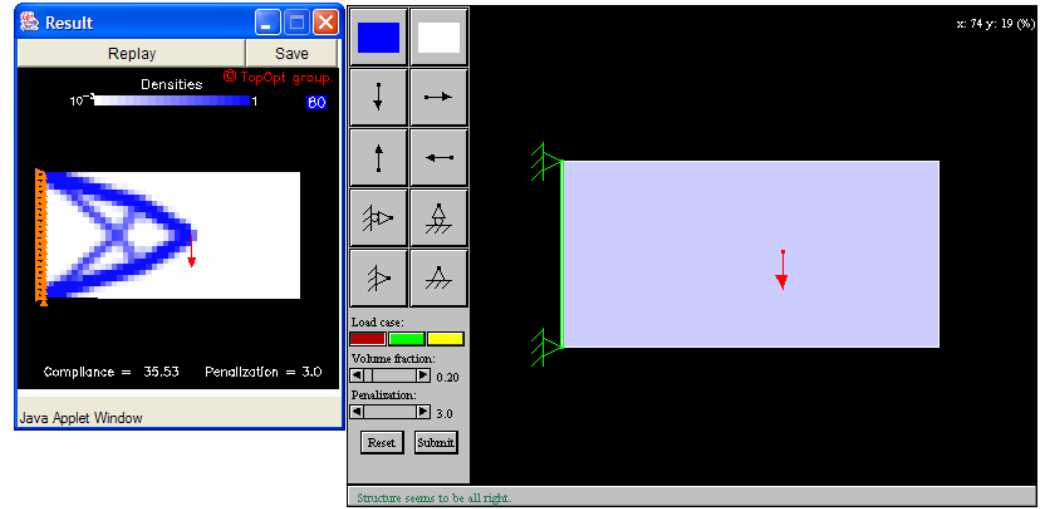

Figure 5: Web-based structural topology optimization (GUI and sample solution)

\section{Student Deliverables}

The entire set of deliverables produced by one of the student teams (Team 5: Racing) is shown in Figure 6. Note, that their hand sketch is different from their CAD model in Phase 1 because a design improvement occurred based on several FEM simulations. In Phase 2, topology optimization found a rough optimum design from which a more refined CAD design was created.

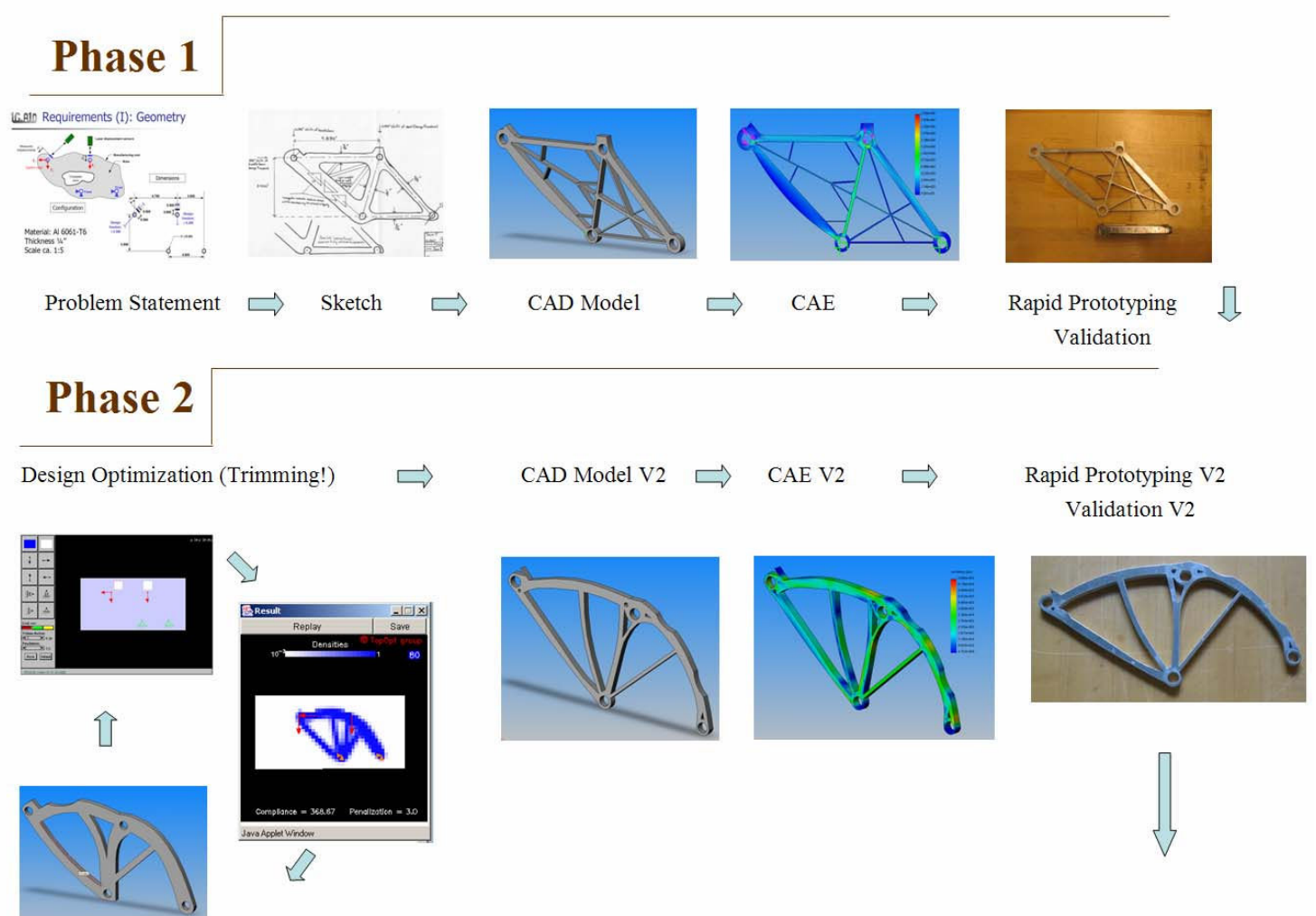

Figure 6: Hand-sketching, CAD, CAE, and manufacturing deliverables by Team 5 
Figure 7 shows deliverables by all teams. The first four bicycle frames (T1-T4), which belong to the consumer division, feature rather simple, slender designs because low manufacturing cost and low mass were important design priorities for them. On the other hand, structural performance metrics were more important for bicycle frames in the specialty and motor divisions (T5-T9). This resulted in more complex, costlier and generally heavier designs obtained by this second group of teams. The variety of the proposed designs is noteworthy.

\begin{tabular}{|c|c|c|c|}
\hline $\begin{array}{c}\text { Team 1 } \\
\text { Family economy }\end{array}$ & $\begin{array}{c}\text { Hand } \\
\text { sketching }\end{array}$ & Ver. 1 & \\
\hline $\begin{array}{c}\text { Team 2 } \\
\text { Family deluxe }\end{array}$ & & \\
\hline $\begin{array}{c}\text { Team 3 } \\
\text { Cross over }\end{array}$ & & \\
\hline $\begin{array}{c}\text { Team } 4 \\
\text { City bike }\end{array}$ & & \\
\hline $\begin{array}{c}\text { Team } 5 \\
\text { Racing }\end{array}$ & & \\
\hline $\begin{array}{c}\text { Team 6 } \\
\text { Mountain }\end{array}$ & & \\
\hline $\begin{array}{c}\text { Team 7 } \\
\text { BMx }\end{array}$ & & \\
\hline $\begin{array}{c}\text { Team } 8 \\
\text { Acrobatic }\end{array}$ & & \\
\hline $\begin{array}{c}\text { Team 9 } \\
\text { Motor bike }\end{array}$ & & \\
\hline
\end{tabular}

Figure 7: Hand-sketches and manufactured parts (versions 1 and 2) by all teams

The performance of each student team's design is shown in Figure 8. All designs in the consumer division (T1-T4) lie in the region where manufacturing cost is low. Bicycle frames in the specialty division (T5-T8) generally have larger mass and natural frequency, at the expense of higher manufacturing cost. These designs have lower displacements, which do not appear in this plot. The Motor division (T9 student team) had to deal with a rectangular, forbidden zone as 
shown in Figure 7. Figure 8 also shows the position of a baseline design, which was constructed by faculty and staff and revealed to the students only at the beginning of Phase 2 .

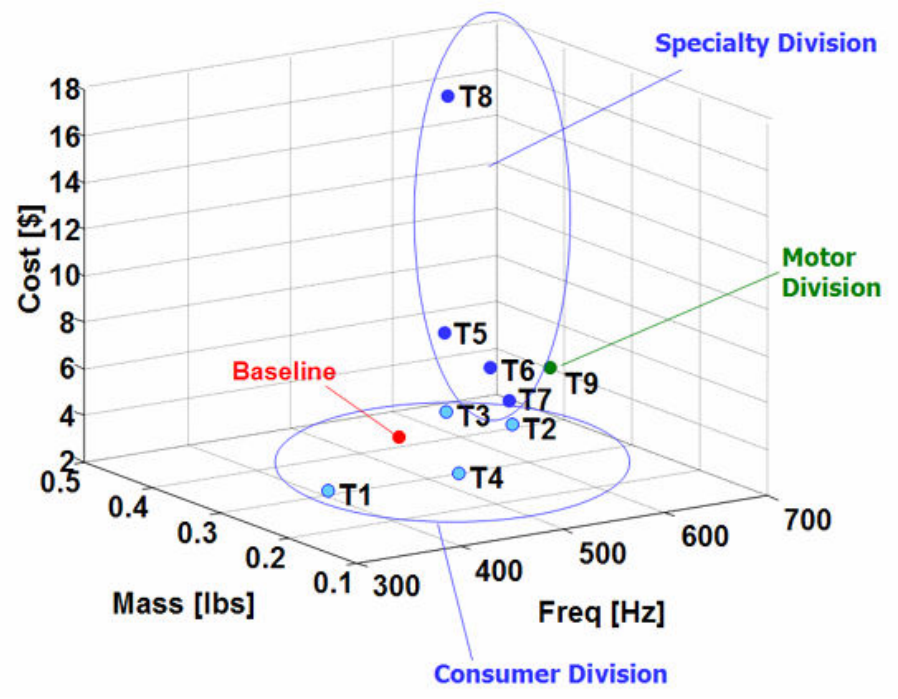

Figure 8: Product attribute overview, T1-9 refers to the student teams

This chart was debated extensively during the final design review. This gave the students a deeper appreciation for the relationship between their design decisions (part configuration and topology, design features, sizing) and the resulting attributes of their product: structural performance, mass and manufacturing cost. At the end of this course, the students were able to articulate the merits of one topology over the other, promote and defend the virtues of their own designs as well as debate the tradeoffs and necessary choices between design objectives.

\section{Course evaluation}

In the last week of the course, an anonymous course evaluation was conducted. The survey consisted of a brief introductory tutorial followed by 5 sections containing questions that needed to be answered by multiple choice as well as essay responses. Ten out of nineteen students participated in the survey. A sample of results from the survey follows:

(1) Amount I have learned, compared to other Aero/Astro courses, has been:

(1: little - 3: medium - 5: much) Score: 3.7

(2) My understanding of design processes has increased:

(1: no — 3: don't know — 5: yes) Score: 4.8

(3) I think that I can apply this course to my work/career:

(1: no - 3: don't know — 5: yes) Score: 4.5

(4) Overall, the subject is worthwhile:

(1: no - 3: don't know - 5: yes) Score: 5

Some of the students' comments were: 
"This course is an excellent idea, and fills a serious need in the undergraduate program, keep developing it, and keep up the good work."

"The course was great. I really enjoyed the fact that we manufactured the part and tested it."

"I think this was an extremely useful class, and I hope it continues because I think that I've learned how to use programs that I will continue to use in the department, and I've gotten some experience in the machine shop, which I could not have had otherwise."

Suggestions for improvement included among others:

"Have each team tackle a more significantly different design challenge."

"Provide for more input from classmates on the design process (semi-formal design reviews before a board of your peers)."

"Make the design slightly more challenging of a problem. If not more challenging, I would have liked to have had the ability to think of a more innovative solution."

"Changing the testing procedure slightly. The testing inaccuracies were frustrating, and it would also have been better to sign up in advance for a time to test the part Version 1."

\section{Discussions and conclusions}

This paper presented a new design course for undergraduate students. The main learning objective of this course is for students to develop a holistic view of and initial competency in engineering design by applying a combination of human creativity and modern computational methods and tools to the synthesis of a structural component. Lectures and hands-on activities are integrated for each phase of the course. Activities include hand sketching, CAD design, Finite Element Analysis, CAM manufacturing, structural testing, and design optimization. Nine different design requirements were given according to each team's hypothetical market segment.

Overall responses from students were very positive. They benefited mainly from the fact that design activities were presented and executed as a coherent stream. Most students may not have experienced the design process in this way before. Allowing the students to carry their design through two iterations, rather than only one, was a crucial element of the pedagogy. Based on the results of the initial offering, it was decided to integrate this course into the permanent MIT course catalogue

For most teams, the testing results did not agree well with static Finite Element simulation results. Likely error sources included the boundary conditions as well as relative compliance between fixture and test article. Improving testing accuracy is a primary task for future years. Improving interactions between teams and early peer review are other areas of improvement. Methods of quantitative assessments and benchmarking of these students against those without design experience would also be beneficial in fine tuning the learning objectives and course procedures. 


\section{Bibliography}

[1] Crawley, E. F., Greitzer, E.M., Widnall, S.E., Hall, S.R., et. al., "Reform of the Aeronautics and Astronautics Curriculum at MIT", ASEE Journal of Engineering Education, Vol. 83, No. 1, pages 47-56, January 1994.

[2] Crawley, E.F., "The CDIO Syllabus: A Statement of Goals for Undergraduate Engineering Education", MIT Dept. of Aeronautics \& Astronautics, Source: http://www.cdio.org, May 2002

[3] W. M. Hollister, E. F. Crawley, and A. R. Amir, "Unified Engineering: A Twenty Year Experiment in Sophomore Aerospace Education at MIT", AIAA-94-0851, 32 $2^{\text {nd }}$ Aerospace Sciences Meeting \& Exhibit, Reno, NV, January 10-13, 1994

[4] Atlla Ertas and Jessec Jones, The engineering design process, Willey, 1993

[5] Kunwoo Lee, Principles of CAD/CAM/CAE systems, Addison Wesley, 1999

[6] Erik Antonsson and Jonathan Cagan (ed), Formal Engineering Design Synthesis, Cambridge, 2001

[7] D. Tcherniak and O. Sigmund, A web-based topology optimization program, Struct Multidisc Optim 22, 179$187,2001$.

[8] Bicycle Manufacturer: Seven Cycles: URL: http://www.sevencycles.com/

\section{Acknowledgments}

This course was made possible thanks to a grant by the alumni sponsored Teaching and Education Enhancement Program (Class of '51 Fund for Excellence in Education, Class of '55 Fund for Excellence in Teaching, Class of ' 72 Fund for Educational Innovation). We gratefully acknowledge the financial support.

The course was approved by the Undergraduate Committee of the MIT Department of Aeronautics and Astronautics on September 19, 2003. We thank Prof. Manuel Martinez-Sanchez and the committee members for their support and constructive suggestions. We also thank Dr. Jaroslaw Sobieski at NASA Langley Research Center for his valuable recommendations.

\section{Dr. IL YONG KIM}

Postdoctoral Associate in the MIT Department of Aeronautics and Astronautics. Dr. Kim's expertise is in design optimization, and he has developed a computational tool that performs design optimization for structural topology optimization and structural plate optimization problems. He has taught CAD and advanced mathematics. He is a 2001 graduate of Korea Advanced Institute for Science and Technology (KAIST).

\section{Prof. OLIVIER DE WECK}

Robert N. Noyce Assistant Professor of Aeronautics and Astronautics and Engineering Systems. Prof. de Weck has taught concept selection and conceptual design optimization in a class on System Architecture (16.882/ESD.34J) at MIT and created a new Multidisciplinary System Design Optimization class (16.888/ESD.77) for graduate level students. His research interests are in Multidisciplinary Design Optimization and System Architecture. Before joining MIT he worked in a CAD/CAE/CAM intensive environment at McDonnell Douglas (now Boeing) on the F/A-18 aircraft program from 1991-1996.

\section{BILL NADIR}

Graduate research assistant in the Department of Aeronautics and Astronautics. He has CAD/CAE experience and has worked for several years as a spacecraft designer in industry (Boeing Satellite Systems). He served as Teaching Assistant for the course during IAP 2004.

\section{PETER YOUNG, COL, USAF (ret.)}

Senior Lecturer in Aeronautics and Astronautics. Colonel Young (ret.) is a senior lecturer in the department of Aeronautics \& Astronautics, specializing in developing and implementing 'hands on' undergraduate engineering projects. He has 29 years service on US Air Force space and missile programs. He is the director of CDIO initiatives in the Department of Aeronautics and Astronautics.

\section{Prof. DAVE WALLACE}

Associate Professor of Mechanical Engineering and Engineering Systems. Prof. Wallace is a tenured, associate professor in the department of mechanical engineering. His research field is integrated computer aided design and industrial design and aesthetics. He teaches product design and industrial design in the department. He is the director of the MIT CADlab. 